\title{
Bond graph modeling of a water-based photovoltaic/thermal (PV/T) collector
}

\author{
Zain Ul Abdin*, Ahmed Rachid \\ Laboratory of Innovative Technologies, University of Picardie Jules Verne, Amiens, 80000, France.
}

\section{ARTICLE INFO}

\section{Keywords:}

Solar photovoltaic/thermal

water heating collector

modeling

theoretical analysis

model validation

\begin{abstract}
A B S T R ACT
This paper deals with photovoltaic-thermal (PV/T) collectors that combine photovoltaic (PV) module and solar thermal (ST) modules to provide heat and electricity simultaneously. The use of a PV/T system not only enhances PV efficiency but also allows to use solar thermal energy for various heating applications. The performance evaluation of the PV/T collectors had been investigated both theoretically and experimentally for the past few years. In this work, we consider a new water-based PV/T configuration by incorporating a tedlar layer and parallel tubes and further investigate its modeling. The aim is to develop a non-linear dynamic model which gives a realistic and reasonable performance of the system. The fundamental equations are determined for the thermal part using a bond graph approach which is a generic and general tool to represent thermal transfers. Simulations are given to highlight the usefulness of the proposed design and its modeling, considering the influence of some external factors (e.g. wind action) and internal geometrical parameters (e.g. insulator thickness). The results indicate that the rise in wind speed can reduce thermal efficiency from $70 \%$ to approximately $40 \%$. The results also show that with an increase in insulator thickness, there is a sudden change in outlet temperature but thicknesses of more than $0.14 \mathrm{~m}$ is not required as the energy losses become constant. The assessment of the electrical and thermal performance of a PV/T collector is taken into consideration for a sample weather condition of southern France. Further, our results are compared to existing experimental and numerical ones from the literature on alternative PV/Ts design to validate and demonstrate the viability and consistency of our model.
\end{abstract}

\section{Introduction}

Photovoltaic/thermal (PV/T) systems are panels which provide heat and electricity at the same time by combining photovoltaic (PV) and solar-thermal (ST) modules. These systems are a good solution to improve the efficiency of a solar collectors and are used for various purposes like heating and cooling combined to electricity generation [U1 Abdin and Rachid, 2021]. In the past various types of PV/T collectors had been proposed with theoretical and experimental analysis. There are various approaches used to extract the heat from solar collector which includes water-based, airbased, nanofluids, and PCM based PV/T collectors. The priority of the PV/T systems is to generate electricity and the photovoltaic efficiency highly depends on the cell temperature. PV/T systems come up with the cooling so ultimately the cell temperature is reduced and the efficiency is increased [Garg and Adhikari, 1998] and by adding the solar thermal module, overall efficiency is increased [Ji et al., 2003]. Theoretically, $80 \%$ efficiency is achievable with more than $60 \%$ thermal from a PV/T collector [Bergene and Løvvik, 1995]. The first work on PV/T systems was presented by Florschuetz [1979] where the main concept of the PV/T collector was presented by assuming a linear correlation between PV cell temperature and its efficiency. Since then, various theoretical and experimental investigations have been presented. We have recently presented a thermal model for an air-based PV/T collector [U1 Abdin and Rachid, 2020] using air as a working fluid. The results indicate that fluid (air) has low heat transfer due to low heat capacity and low thermal conductivity. The use of air as a working fluid is cheaper and easier but the use of water as a working fluid is more efficient for hot weather conditions. The performance evaluation of a PV/T system using water as a coolant was conducted by He et al. [2006] where it is concluded that water-based PV/T systems are suitable for the warm climatic applications. In addition, the results obtained were encouraging with a daily thermal efficiency of $40 \%$. A comparative study was done by Malvi et al. [2011], where a 1-D energy balance model is presented incorporating PCM. Using the 1-D energy balance model, the performance of the panel is evaluated using PCM. The model is divided into five

\footnotetext{
*Corresponding author

zain.ul@u-picardie.fr (Z.U. Abdin)

ORCID(s): 0000-0003-2670-4287 (Z.U. Abdin)
} 


\section{Nomenclature}

$\begin{array}{ll}\mathrm{PCM} & \text { phase change material } \\ \mathrm{PV} / \mathrm{T} & \text { photovoltaic/thermal } \\ \text { Symbols } & \\ A_{\text {mod }} \quad \text { module area of a PV panel } \\ d_{i} & \text { inner diameter of the tube } \\ d_{o} & \text { outer diameter of the tube } \\ I_{\text {sun }} & \text { solar radiation } \\ l & \text { thickness } \\ M & \text { mass } \\ T & \text { temperature } \\ V_{w} & \text { wind speed } \\ x & \text { length of the panel } \\ y & \text { width of the panel } \\ \text { Greek letters } \\ \alpha & \text { absorptivity } \\ \beta & \text { packing factor }\end{array}$

$\begin{array}{ll}\beta_{p} & \text { temperature coefficient } \\ \epsilon & \text { emissivity } \\ \lambda & \text { thermal conductivity } \\ \eta_{r e f} & \text { reference efficiency } \\ \tau & \text { transmissivity } \\ \text { Subscripts } \\ a m & \text { ambient } \\ c & \text { PV cell } \\ g & \text { glass cover } \\ i & \text { thermal insulator } \\ m & \text { tube } \\ r & \text { absorber } \\ s & \text { sky } \\ t & \text { tedlar } \\ w & \text { fluid (water) }\end{array}$

layers; glass cover, PV cell layer, copper plate, PCM layer and, insulated frame. It is concluded that by increasing the PCM thickness to a certain limit the output increases by $6.5 \%$, and $9.5 \%$ when comparing it with PV only system. Thermal performance of solar installations have been studied by Cristofari et al. [2002] where technical characteristics are optimized, and the influence of various parameters is presented theoretically. A number of different configurations and multiple thermal models have been reported with the influence of various parameters on the performance of the $\mathrm{PV} / \mathrm{T}$ systems.

Dubey and Tiwari [2008] consider two flat plate collectors which are interconnected in series and connected to a storage tank. $60 \%$ area of one collector is integrated by the PV module and remaining with glazing, the second collector is fully covered by glazing. Under this, there is an absorber, followed by metallic plates through which water flows, and finally at the bottom is an insulator layer. The result indicates that by increasing glazing, efficiency increases from $33 \%$ to $64 \%$. Chaabane et al. [2014] proposed two different numerical models and study the effect of PCM on thermal performance by integrating PCM directly in the collector. Based on control a volume finite difference approach, dynamic model with water as a working fluid is developed by Chow [2003] and the energy balance matrix is obtained. The collector is divided into various sections and each section consists of a single water tube. The PV cell layer is in direct contact with the water tube. There is direct heat transfer from the PV plate to the tube. A performance evaluation of a water-based PV/T collector is done by Tiwari and Sodha [2006] and numerical results are then validated by the experimental results. The simulated results predict a daily thermal efficiency of around $58 \%$, which is slightly less than the experimental value of $61.3 \%$. Zondag et al. [2002] presented four different numerical models with three steady-state models and one dynamical model. The model was built on a single pipe winding (twisting like a snake) to measure the performance of the system. The model is full time-dependent quasi 3D and includes second-order differentiations. Absorber plate and the PV laminate are split up in two directions; parallel to the flow and perpendicular to the flow whereas the top layer is separated; parallel to the flow.

In this paper, a bond graph approach is used to model the thermal part of a water-based PV/T collector by incorporating a tedlar layer and parallel tubes. The performance of a PV/T collector is characterized by its water temperature rise, thermal and electrical efficiencies and the net available energy. At the same time, the sensitivity of geometrical parameters (e.g. insulator thickness) and influence of some external factors (e.g. wind action) is analyzed to improve design and performance of a PV/T collector. Further, the assessment of electrical and thermal performance of a PV/T collector is taken into consideration for a sample weather condition of southern France. Finally, current model is verified by comparing the results with several studies in the literature. 
(a)

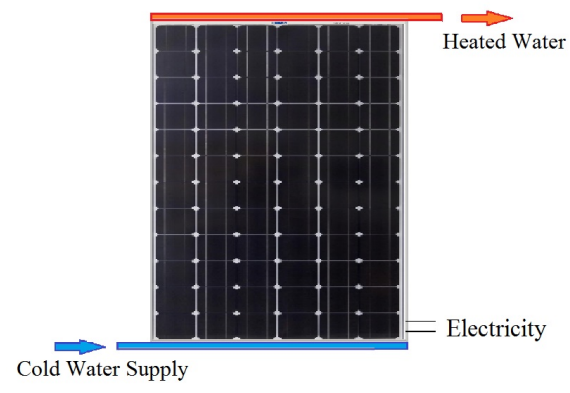

(b)

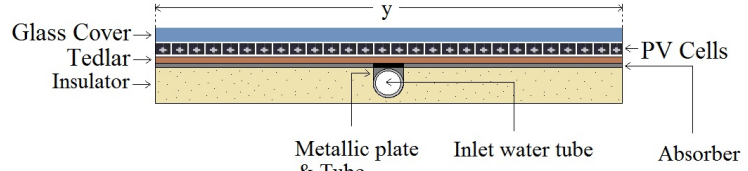

(d)
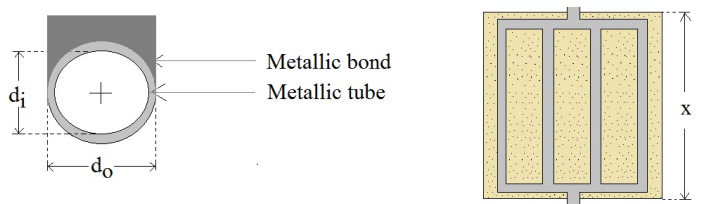

Figure 1: (a) Water-based PV/T collector. (b) cross-sectional view of the collector. (c) metallic tube and bond. (d) $\mathrm{PV} / \mathrm{T}$ collector flow dynamics.

The paper is organized as follows; a bond graph modeling technique is presented in section 2 to model the thermal part of a water-based PV/T collector. Section 3 provides the simulation results and discussion. It also provides valuable information regarding the influence of various parameters such as thickness, mass flow rate, wind speed, and solar radiation on the outlet fluid temperature. The paper ends with a conclusion and some perspectives.

\section{Modeling}

There exist several papers in which the performance of a PV/T is studied and most of the studies are concentrated on the experimental performance of the PV/T system. The focus is to present a non-linear dynamic model of a waterbased PV/T collector which gives a realistic and reasonable performance of the system. In a PV/T panel configuration, cold water is supplied from one end of the panel, and warm water is collected along with the electrical gain from the other end of the panel as shown in Fig. 1(a). Fig. 1(b) shows the thermal model of the panel, composed of several layers; a protective glass layer for PV cells, solar cells layer, protective tedlar layer under PV cells, absorber, metallic tube with bond, water channel, and thermally insulated frame to reduce heat losses. There are four parallel water tubes available through which fluid flows and these tubes are fitted and pressed with the bond to the insulator layer as shown in Fig. 1(b). Water is inserted from a single point, then it is distributed equally to all the tubes and warm water is collected from the other end of the panel as shown in Fig. 1(d). The governing equations of the thermal model were determined using a bond graph technique. Few assumptions have been considered for the thermal model such as heat transfer between the ground and the panel is over sighted and pressure losses are neglected, the temperature is assumed to be homogeneous for each layer. Radiation heat exchange at the bottom and edge losses are neglected because the temperature difference at the bottom is small.

A bond graph is a graphical sketch of a physical system, represented by symbols and lines. It also consists of elements of resistance, compliance, and inertance which are interconnected by junctions, bonds, and flow of energy or power. Effort $(e)$ and flow $(f)$ are two power conjugated variables in the bond graph and in physical domains the way of selection of these two variables is different. There can be multiple domains and this system contains two subsystems i.e. thermal and hydraulic subsystem. In a thermal subsystem, the effort variable is represented by temperature whereas flow variable as heat flow $(\dot{Q})$, solar flow $(G)$ and enthalpy $(\dot{H})$. In a hydraulic subsystem, the pressure $(P)$ is an effort variable and mass flow $(\dot{m})$ is flow variable. Resistance $(R)$, compliance $(C)$, and inertance $(I)$ are classified as a single port and contain no source of power, convert the supplied energy into stored or dissipated energy, and are classified as passive elements. Sources are the active elements that provide power to the system, they are single port and they can be either flow source $\left(S_{f}\right)$ or effort source $\left(S_{e}\right)$. Junctions represent system topology, can connect two or more bonds and are of two kinds, "0-junction" and a "1-Junction". In 0-Junction, all connected bonds constrained to have the same efforts whereas flows sum up to zero. 1-junction has equality of flows and the algebraic sum of efforts is zero. A bond graph can include multiple domains, when a fluid is flowing and heat transfer is also involved, thermal and hydraulic energies are combined and are represented by a circle around a bond as shown in a bond graph.

For 0-Junction, effort equation [Borutzky, 2009] is respectively given as:

$$
e_{i 1}=\ldots=e_{i m}=e_{o 1}=\ldots=e_{o n}
$$




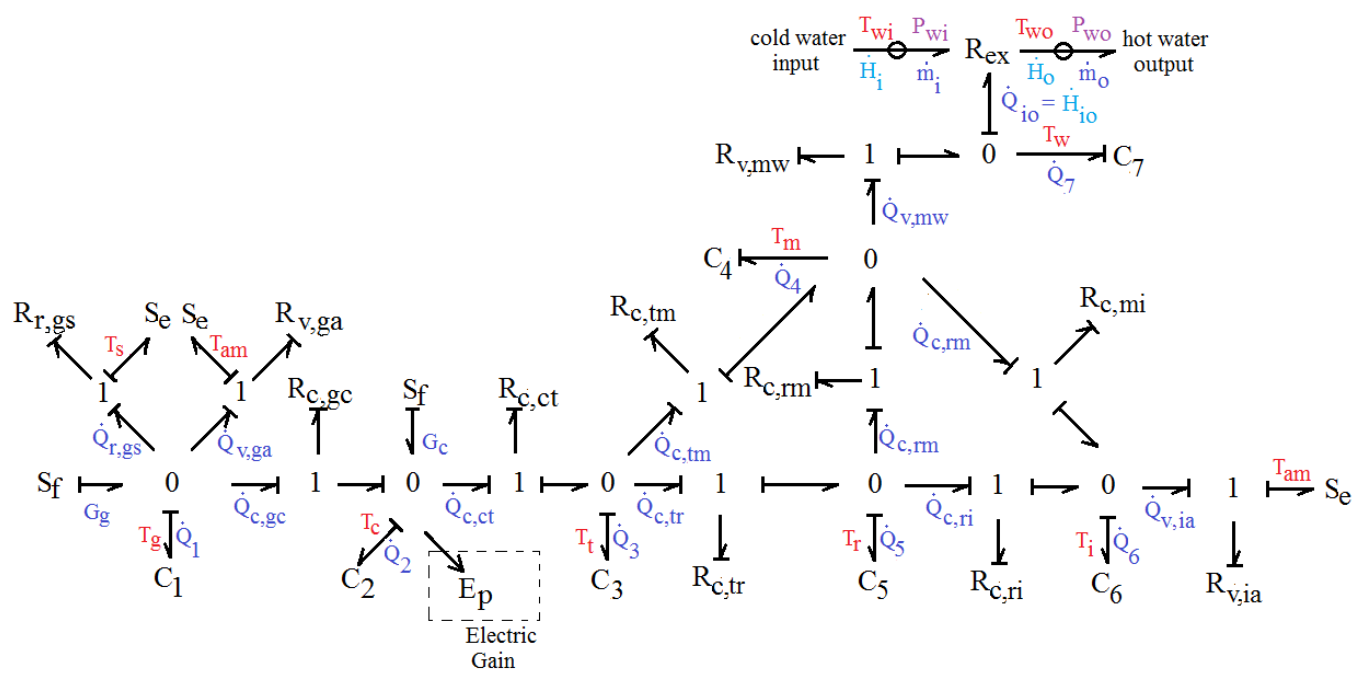

Figure 2: Bond graph model of the $\mathrm{PV} / \mathrm{T}$ collector.

and has flow equation

$$
\sum_{k=1}^{m} f_{i k}=\sum_{k=1}^{n} f_{o k}
$$

For 1-Junction, flow equation is respectively given as:

$$
f_{i 1}=\ldots=f_{\text {im }}=f_{o 1}=\ldots=f_{\text {on }}
$$

and has effort equation

$$
\sum_{k=1}^{m} e_{i k}=\sum_{k=1}^{n} e_{o k}
$$

Each layer is break up into two pieces: one is dissipated by conduction and the other is stored by the layer. 0junction relates to the compliance element whereas 1 -junction relates to the resistance element. Relationship between generalized effort and generalized flow corresponding to resistance and compliance elements are written as (5) and (6):

$$
f(t)=\frac{1}{R} e(t)
$$

where

$$
e(t)=\frac{1}{C} \int f(t) d t
$$

When two objects with two different temperatures are in contact with each other, heat energy pass between them. In hot materials, molecules move faster and hit the cold object molecule's which are incontact with the hot object. Heat transfer coefficient $(h)$ is the inverse of thermal heat flow and using (5) thermal heat flow for the resistance element between two layers $a$ and $b$ is given by:

$$
\dot{Q}=\frac{1}{R}\left(T_{a}-T_{b}\right) A
$$


Using (6), temperature ( $T$ ) of each layer with thermal heat capacity $(C)$ and thermal heat flow $(\dot{Q})$ accumulated by each layer can be written as:

$$
T=\frac{1}{C} \int \dot{Q} d t
$$

Thermal heat capacity with density $(\rho)$, volume $(V)$ and specific heat capacity $\left(C_{l}\right)$ for each layer is given by:

$$
C=\rho V C_{l}
$$

At a rate of $I$ in Watts, solar radiation energy denoted by $G_{g}$, absorbed by the glass cover is $A_{\text {mod }} \alpha_{g} I_{\text {sun }}$ and the energy $G_{c}$ is absorbed by the PV cell layer and is $A_{\text {mod }} \tau_{g} \alpha_{c} I_{s u n} \beta$, where $\alpha_{g}$ and $\alpha_{c}$ are absorptance of glass cover and PV cell whereas $\tau_{g}$ is the transmittance of the glass cover. There is a change in temperature and in enthalpy in the water tube during heat exchange and the energy gain [Bergene and Løvvik, 1995] can be written as:

$$
\dot{H}_{o i}=\dot{H}_{o}-\dot{H}_{i}=\dot{m}_{w} C_{w}\left(T_{w o}-T_{w i}\right)
$$

Glass cover is the top layer of the PV/T collector and the purpose of adding the glass cover is to protect the PV cell layer and reduce the heat loss to ambient. This will eventually improve the thermal efficiency of the system. The equation for glass layer using (7) and (8) is respectively given by:

$$
M_{g} C_{g} \frac{d T_{g}}{d t}=A_{m o d}\left[\alpha_{g} I_{s u n}-h_{r, g s}\left(T_{g}-T_{s}\right)-h_{v, a m}\left(T_{g}-T_{a m}\right)-h_{c, g c}\left(T_{g}-T_{c}\right)\right],
$$

where module area is written as;

$$
A_{\text {mod }}=x y
$$

$R_{r, g s}$ is the radiative heat flow between sky and glass cover. Where $\sigma$ is Stefan Boltzmann constant and radiation heat transfer coefficient between glass layer and sky [Hegazy, 2000] is given by:

$$
h_{r, g s}=\sigma \epsilon_{g} \frac{\left(T_{g}^{2}-T_{s}^{2}\right)\left(T_{c}^{2}+T_{s}^{2}\right)}{\left(T_{g}-T_{a m}\right)}
$$

To take atmosphere into account, sky temperature $\left(T_{s}\right)$ [Chaabane et al., 2014] is given by Swinbank (1963) associate's sky temperature with local air temperature.

$$
T_{s}=0.0552 T_{a m}^{1.5}
$$

The heat convection takes place at the top and bottom surfaces. Convective heat coefficient strongly depends on the wind speed $\left(V_{w}\right)$ and is given by a dimensional equation [Duffie and Beckman, 2013].

$$
h_{v, a m}=5.7+3.8 V_{w}
$$

$R_{c, a b}$ is the conduction heat flow and conductive heat transfer coefficient between two parallel layers (a and b) [Slimani et al., 2017] is given as;

$$
h_{c, a b}=\frac{1}{\left(\frac{l_{a}}{\lambda_{a}}+\frac{l_{b}}{\lambda_{b}}\right)},
$$

The equation for PV cell layer using (7) and (8) is respectively given by:

$$
M_{c} C_{c} \frac{d T_{c}}{d t}=A_{\text {mod }}\left[\tau_{g} \alpha_{c} I_{s u n} \beta+h_{c, g c}\left(T_{g}-T_{c}\right)-h_{c, c t}\left(T_{c}-T_{t}\right)\right]-E_{p}
$$

Electric power $\left(E_{p}\right)$ produced by PV panel [Florschuetz, 1979] can be respectively written as (18).

$$
E_{p}=I_{\text {sun }} A_{\text {mod }} \eta_{c}=I_{\text {sun }} A_{\text {mod }} \eta_{\text {ref }}\left[1-\beta_{p}\left(T_{c}-T_{c, \text { ref }}\right)\right]
$$


The equation for tedlar layer using (7) and (8) is respectively given by:

$$
M_{t} C_{t} \frac{d T_{t}}{d t}=A_{m o d} h_{c, c t}\left(T_{c}-T_{t}\right)-A_{t m} h_{c, t m}\left(T_{t}-T_{m}\right)-A_{t r} h_{c, t r}\left(T_{t}-T_{r}\right),
$$

where

$$
A_{t m}=d_{o} x
$$

and

$$
A_{t r}=\left(y-d_{o}\right) x
$$

The equation for absorber using (7) and (8) is respectively given by:

$$
M_{r} C_{r} \frac{d T_{r}}{d t}=A_{t r} h_{c, t r}\left(T_{t}-T_{r}\right)-A_{r m} h_{c, r m}\left(T_{r}-T_{m}\right)-A_{r i} h_{c, r i}\left(T_{r}-T_{i}\right),
$$

where

$$
A_{r m}=l_{r} x
$$

and

$$
A_{r i}=\left(y-d_{o}\right) x
$$

The equation for tube using (7) and (8) is respectively given by:

$$
M_{m} C_{m} \frac{d T_{m}}{d t}=A_{t m} h_{c, t m}\left(T_{t}-T_{m}\right)+A_{r m} h_{c, r m}\left(T_{r}-T_{m}\right)-A_{m i} h_{c, m i}\left(T_{m}-T_{i}\right)-A_{m w} h_{v, m w}\left(T_{m}-T_{w}\right),
$$

where

$$
A_{m i}=\left(d_{o} x+\frac{\pi d_{o} x}{2}\right)
$$

The inside area of the tube $\left(A_{w}\right)$ can be written as:

$$
A_{w}=\pi d_{i} x
$$

and the area of the bond $\left(A_{m o}\right)$ with width of bond $\left(w_{m o}\right)$

$$
A_{m o}=w_{m o} x
$$

In the heat transfer processes, convective heat coefficients add inversely in series and overall heat transfer coefficient with contact area, and with a bond thickness $\left(l_{m o}\right)$ and thermal conductivity $\left(\lambda_{m o}\right)$ is:

$$
\frac{1}{h_{v, w m} A_{w m}}=\frac{1}{h_{w} A_{w}}+\frac{l_{m o}}{\lambda_{m o} A_{m o}},
$$

where heat transfer coefficient for fully developed laminar flow can be written as $h_{w}$ [Chow, 2003].

$$
h_{w}=\frac{4.364 \lambda_{w}}{d_{i}}
$$

The equation for water channel using (7), (8) and (10) is respectively given by:

$$
M_{w} C_{w} \frac{d T_{w}}{d t}=A_{m w} h_{v, m w}\left(T_{m}-T_{w}\right)+\dot{m}_{w} C_{w}\left(T_{w i}-T_{w o}\right)
$$


$T_{w i}$ is the inlet temperature to the channel whereas $T_{w o}$ is the output temperature of the water channel and the mean temperature $\left(T_{w}\right)$ is given as:

$$
T_{w}=\frac{\left(T_{w i}+T_{w o}\right)}{2}
$$

The equation for insulator layer using (7) and (8) is respectively given by:

$$
M_{i} C_{i} \frac{d T_{i}}{d t}=A_{m i} h_{c, m i}\left(T_{m}-T_{i}\right)+A_{r i} h_{c, r i}\left(T_{r}-T_{i}\right)-A_{m o d} h_{v, i a m}\left(T_{i}-T_{a m}\right)
$$

$R_{v, \text { iam }}$ is the convective heat flow and convective heat transfer coefficient between insulator and surrounding is given as;

$$
\frac{1}{h_{v, \text { iam }}}=\frac{1}{h_{v, \text { am }}}+\frac{l_{i}}{2 \lambda_{i}}
$$

Thermal efficiency is defined as ratio of useful energy gain to the incident solar energy over the same period of time. Applying useful energy gain (10), the thermal performance of PV/T collector [M'Sirdi et al., 2018] is;

$$
\eta_{t h}=\frac{\dot{m}_{w} C_{w}\left(T_{w o}-T_{w i}\right)}{A_{\text {mod }} I_{\text {sun }}}
$$

$\mathrm{PV}$ efficiency of the PV/T panel is defined as ratio of electrical gain to the total incident energy and written as;

$$
\eta_{\text {ele }}=\frac{E_{p}}{A_{\text {mod }} I_{\text {sun }}}
$$

The overall efficiency $\eta_{o v}$ is the sum of thermal efficiency (35) and electrical efficiency (36) of a PV/T collector and can be calculated as follows:

$$
\eta_{o v}=\eta_{e l e}+\eta_{t h}
$$

Thermal efficiency mainly depends on the solar radiation available whereas electrical efficiency highly depends on the cell temperature. A high cell temperature will decrease the photovoltaic efficiency so it is important to have not very high cell temperature.

\section{Results and discussion}

\subsection{Simulation studies of a PV/T model}

Performance of PV/T collector depends on several parameters: ambient temperature, solar radiation, mass flow rate, wind speed, fluid flowing (e.g. water or air) and thickness of various layers. Ambient temperature $\left(T_{a m}\right)$ and solar radiation $\left(I_{\text {sun }}\right)$ are presented under a sample of southern France climatic conditions in Fig. 3. The sample is taken during daylight because of strong solar radiation and for the rest of the day; the solar radiation is hardly at all. Both solar radiation and ambient temperature increase with time and reach a maximum value around noon. The ambient temperature reaches to a maximum value of $35^{\circ} \mathrm{C}$ and solar radiation goes to $870 \mathrm{~W} / \mathrm{m}^{2}$, respectively, at the solar noon.

The Matlab program is used for the proposed numerical design and climatic parameters. The obtained results are provided in Fig. 4-9. The results obtained from the proposed model are then compared with previous studies in the literature and are provided in Table 1 and Fig. 10. Values of absorptivity, transmissivity and emissivity for the glass and cell layers of a PV/T collector are taken as: $\alpha_{g}=0.06, \tau_{g}=0.8, \epsilon_{g}=0.93$ and $\alpha_{c}=0.85$. The temperature profile for glass cover, PV cell, tedlar, absorber, insulator, metallic tube and fluid is shown in Fig. 4. Temperatures rise with the increase in solar radiation and ambient temperature, and falls with the drop in ambient temperature and solar radiation as illustrated. Ambient temperature and solar radiation vary, depending on the weather conditions. During the day time, the maximum solar radiation available is $870 \mathrm{~W} / \mathrm{m}^{2}$ which occurs at 13:00 (local time) when the ambient temperature is maximum too. 


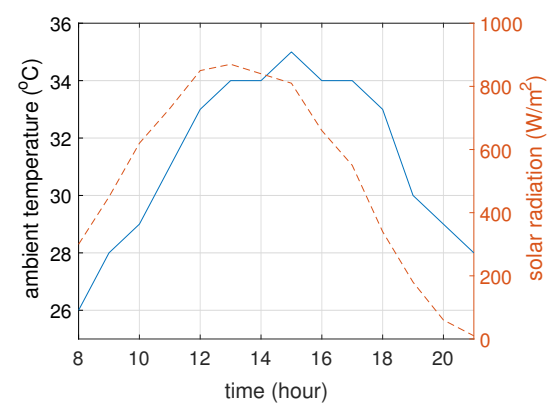

Figure 3: Daily evolution of solar radiation and ambient temperature.

The temperature of PV module components is highest around this point with the PV cell temperature goes to approximately $53^{\circ} \mathrm{C}$. It is obvious that the $\mathrm{PV}$ cell temperature is higher than the other components temperature whatever the value of solar radiation and ambient temperature. The inclussion of glass cover on top not only protects the PV module but causes an increase in PV cell temperature due to which the fluid temperature rises. However, the PV efficiency drops with rise in every $1^{\circ} \mathrm{C}$ cell temperature. Further, the fluid temperature rises to $49^{\circ} \mathrm{C}$ as shown in Fig. 4(b) with the inlet water temperature of $25^{\circ} \mathrm{C}$, mass flow rate is kept constant at $0.005 \mathrm{~kg} / \mathrm{sec}$ and insulaton thickness of $0.12 \mathrm{~m}$. It can also be seen that each component in the PV/T collector has a higher temperature than the ambient temperature.

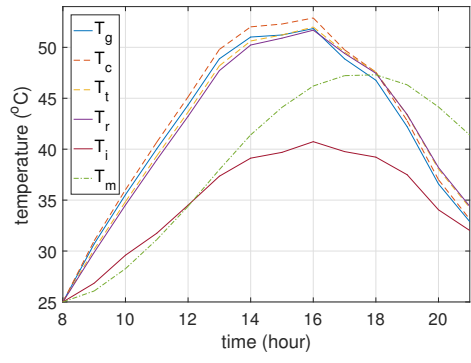

(a)

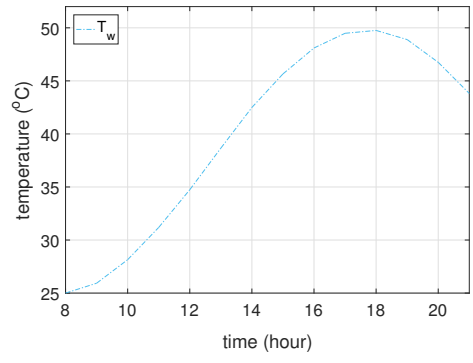

(b)

Figure 4: (a) Daily evolution of temperatures $\left(T_{g}, T_{c}, T_{t}, T_{r}, T_{i}\right.$ and $\left.T_{m}\right)$. (b) Daily evolution of output temperature $\left(T_{w}\right)$.

A step-change in solar radiation is used in order to know the dynamic response and is given in Fig. 5. The solar radiation is reduced from $200 \mathrm{~W} / \mathrm{m}^{2}$ to $50 \mathrm{~W} / \mathrm{m}^{2}$ and results indicate that the response is not sudden; it takes time to reach the destination point. Moreover, it can be seen that the temperature rise is faster than the temperature drop.

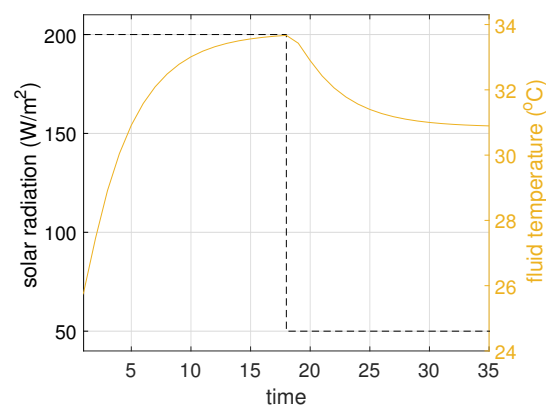

Figure 5: Fluid temperature with a step change in solar radiation.

An analysis of Fig. 6 illustrates, increase in an insulator thickness leads to an increase in fluid temperature but there 
is a sudden change in outlet temperature if the thickness is less than $0.08 \mathrm{~m}$. Additionally, for economical reasons, thicknesses of more than $0.14 \mathrm{~m}$ is not required as the energy losses becomes constant.

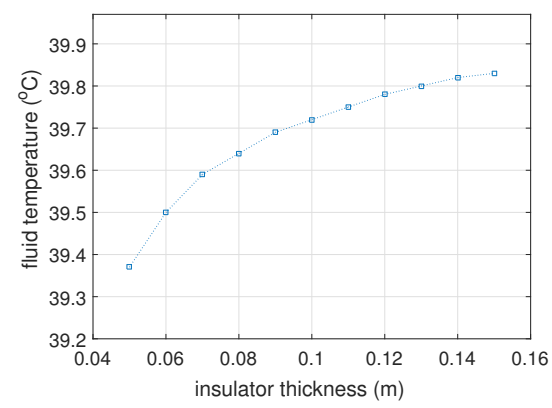

Figure 6: Influence of insulator thickness on the output temperature $\left(T_{w}\right)$.

Wind speed has a major influence on the performance of the PV/T collector especially during the summer season. This is mainly due to the fact that convective exchange is higher. The results in Fig. 7 show that an increase in wind speed, leading to degradation of thermal efficiency (35). The thermal efficiency drops from $70 \%$ to approximately $40 \%$ with the wind speed of $1 \mathrm{~m} / \mathrm{sec}$ to $5 \mathrm{~m} / \mathrm{sec}$. It is also noticed that with solar radiation of 500 and $750 \mathrm{~W} / \mathrm{m}^{2}$ and wind speed of $1 \mathrm{~m} / \mathrm{sec}$ to $5 \mathrm{~m} / \mathrm{sec}$, the thermal efficiency varies between $32 \%$ and $70 \%$.

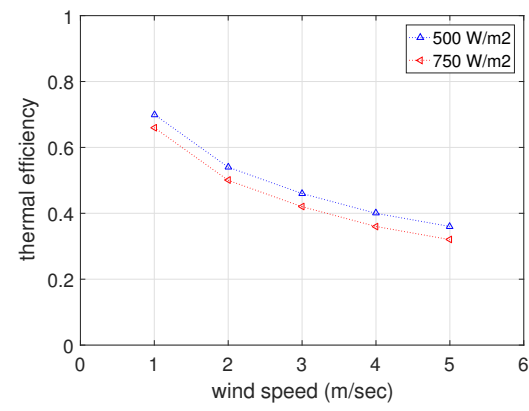

Figure 7: Influence of wind speed on thermal efficiency.

For cost effectiveness of a PV/T collector, selection of mass flow rate is an important factor for the pump capacity. Fig. 8 illustrates the effect of mass flow rate on the outlet temperature by varying solar radiation. The results indicate that with an increase in mass flow rate, temperature decreases. An interesting observation is that at lower mass flow rates the temperature rise/drop is getting smaller. Further, an increase in solar radiation, the temperature difference between two different mass flow rates increases.

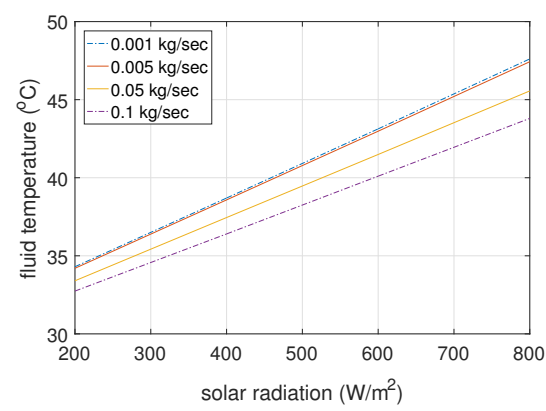

Figure 8: Influence of mass flow rate on the output temperature $\left(T_{w}\right)$. 
The PV efficiency of a collector is respectively given in Fig. 9. Here, the results showed that with an increase in solar radiation and cell temperature (Fig. 4) the PV efficiency decreases, and by the end of the day, it increases with the decrease in solar radiation and cell temperature under the same mass flow rate. The average PV efficiency during the daytime is $10.82 \%$ with values ranging between a minimum of $10.28 \%$ and a maximum of $11.56 \%$.

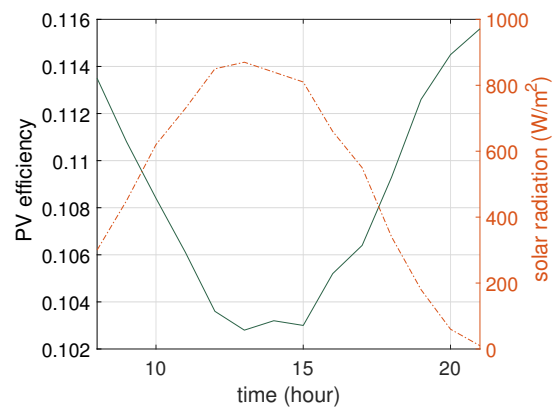

Figure 9: Hourly variation of PV efficiency and solar radiation.

\subsection{Validation and verification of $P V / T$ model}

The numerical results in this work are compared with the ones found in the literature [Dubey and Tiwari, 2008, Tiwari and Sodha, 2006, Chow, 2003, Zondag et al., 2002] and are summarized in Table 1.

The hybrid PV/T collector has been experimentally studied by Dubey and Tiwari [2008], equipped with a glass cover encased in an aluminum metallic box with $0.1 \mathrm{~m}$ glass wool insulation below the absorber to reduce bottom losses. The experimental value of cell temperature goes to $52^{\circ} \mathrm{C}$ whereas outlet temperature was found at $43^{\circ} \mathrm{C}$ with the same insulation and weather conditions. However, if the mass flow rate in the current model is increased from $0.005 \mathrm{~kg} / \mathrm{sec}$ to $0.09 \mathrm{~kg} / \mathrm{sec}$ the outlet temperature drops close to $43^{\circ} \mathrm{C}$ reported experimentally.

The numerical results obtained in the present study were also compared with other numerical and experimental results found in Tiwari and Sodha [2006]. The reduction in insulator thickness and solar radiation drops the outlet temperature so with insulator thickness of $0.05 \mathrm{~m}$ and solar radiation of $812 \mathrm{~W} / \mathrm{m}^{2}$, the obtained results are in good agreement.

Furthermore, the values computed by the developed model with the same mass flow rate were compared with the values reported in Chow, 2003. The outlet water temperature values have a small difference due to the difference in solar radiation.

Our data is also compatible with the experimental results in Zondag et al. [2002]. The two parameters due to which the outlet temperature difference is high are insulation thickness which is $0.12 \mathrm{~m}$ (resp. an ambient temperature of $34^{\circ} \mathrm{C}$ ) in this study compared to $0.02 \mathrm{~m}$ (resp. $20^{\circ} \mathrm{C}$ in Zondag et al. [2002]). On the other hand, their results are in good agreement with ours when the solar radiation is taken as $800 \mathrm{~W} / \mathrm{m}^{2}$ with ambient temperature $20^{\circ} \mathrm{C}$ and insulator thickness of $0.02 \mathrm{~m}$. It is worth it to mention that the highest PV efficiency achieved in the current work is close to the maximum value obtained experimentally in other studies in the literature referred in Table 1.

Table 1

Summary of results for the current work and other studies in literature.

\begin{tabular}{llllllll}
\hline Reference & $T_{w}\left({ }^{o} \mathrm{C}\right)$ & $\dot{m}_{w}(\mathrm{~kg} / \mathrm{sec})$ & $I_{\text {sun }}\left(\mathrm{W} / \mathrm{m}^{2}\right)$ & $T_{a m}\left({ }^{o} \mathrm{C}\right)$ & $T_{c}\left({ }^{o} \mathrm{C}\right)$ & $l_{i}(\mathrm{~m})$ & $\eta_{\text {ele }}(\%)$ \\
\hline Current study & 49 & 0.005 & 870 & 34 & 52 & 0.12 & 10.28 \\
Dubey and Tiwari [2008] & 43 & 0.09 & Spring (Delhi) & & $\simeq 50$ & 0.1 & $10.5-11$ \\
Tiwari and Sodha [2006] & $\simeq 44$ & 0.005 & 812 & 35 & $\simeq 50$ & 0.05 & - \\
Chow, 2003 & 46.4 & 0.005 & 800 & - & 51.72 & - & $\simeq 9$ \\
Zondag et al. [2002] & 40 & 0.005 & 800 & 20 & - & 0.02 & 9.7 \\
\hline
\end{tabular}

The hybrid PV/T system has also been experimentally studied by Huang et al. [2001] to understand the performance of an integrated photovoltaic and thermal solar system (IPVTS) and the experimental variations of solar radiation 
and ambient temperature along with PV cell temperature and fluid temperature obtained is shown in Fig. 10. The experimental climatic data for a sunny day of May is shown in Fig. 10(a) and is used in our proposed model to know the hourly variation of PV cell temperature and fluid temperature as illustrated in Fig. 10(b). It should be noted that in numerical simulation, the wind speed was taken with a value of $3 \mathrm{~m} / \mathrm{s}$, insulator thickness is $0.1 \mathrm{~m}$, and water mass flow rate is taken as $0.005 \mathrm{~kg} / \mathrm{s}$. The results show that the numerical simulations are fairly close to the experimental data with a small difference. This difference is mainly due to the fact that all the parametric values (e.g. thickness of the layers and material used for absorber and insulator etc), geometry, and design used in this study might be different from experimental setup built-in experimental studies. As a general conclusion, the simulation results founded by the numerical model developed in this study and the experimental studies [Huang et al., 2001] validate the viability of the proposed model.

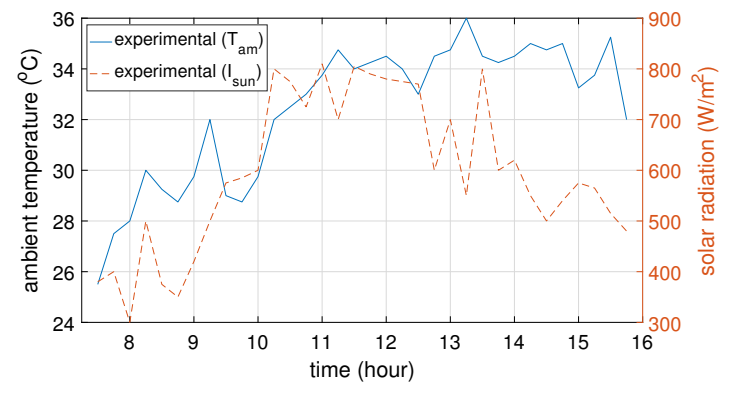

(a)

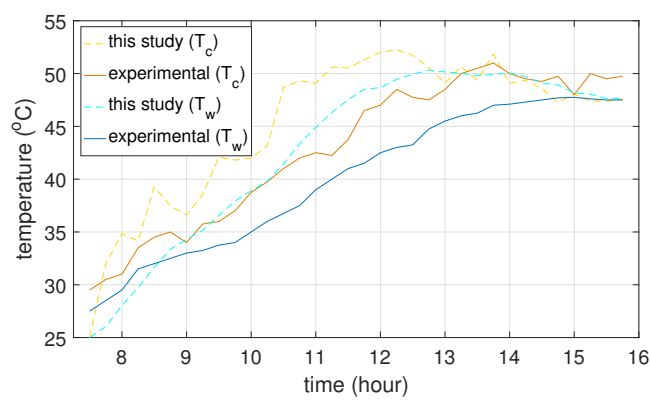

(b)

Figure 10: (a) Daily evolution of solar radiation and ambient temperature experimentally. (b) Daily evolution of temperatures $\left(T_{c}\right.$ and $\left.T_{w}\right)$ both experimentally (experimental studies) and theoretically (this study).

It can be observed in both Table 1 and Fig. 10 that there is good compatibility between the experimental results and the simulated results obtained using the above proposed model.

\section{Conclusion}

In this paper, we have addressed a complete thermal model of a water-based PV/T collector including a tedlar layer and parallel water tubes. The modeling has been performed using a bond graph technique which can be adapted to other PV/Ts' design and configuration. Simulations have been implemented to highlight the coherence and the usefulness of the proposed model. Its consistency has been validated by comparison to other existing PV/Ts design alternatives.

A sensitivity analysis of the physical and external variables have also been performed and the following conclusions can be drawn: The outlet water temperature rise is faster than the temperature drop with a step change in solar radiation; The insulator thickness is an important design parameter, influencing the performance of a PV/T collector. The higher outlet water temperature is achieved with the insulator thickness of more than $0.08 \mathrm{~m}$ but for economical reasons, thicknesses of more than $0.14 \mathrm{~m}$ is not required as the energy losses becomes constant.

The PV/T collector shows higher thermal efficiency if the wind speed is low and the thermal efficiency can be enhanced with the increase of water specific mass flow rate. The thermal efficiency drops from $70 \%$ to less than $40 \%$ with an increase in wind speed from $1 \mathrm{~m} / \mathrm{sec}$ to $5 \mathrm{~m} / \mathrm{sec}$; The thermal energy obtained from the PV/T collector can also be used for various heating applications and for cooling purpose by utilizing the electricity generated by the PV module to run a heat pump.

Further investigations are in progress to design control algorithms in order to optimize the operational performance of the PV/T.

\section{References}

Trond Bergene and Ole Martin Løvvik. Model calculations on a flat-plate solar heat collector with integrated solar cells. Solar energy, 55(6): 453-462, 1995.

Wolfgang Borutzky. Bond graph modelling and simulation of multidisciplinary systems-an introduction. Simulation Modelling Practice and Theory, 17(1):3-21, 2009. 
Monia Chaabane, Hatem Mhiri, and Philippe Bournot. Thermal performance of an integrated collector storage solar water heater (icsswh) with phase change materials (pcm). Energy conversion and management, 78:897-903, 2014.

TT Chow. Performance analysis of photovoltaic-thermal collector by explicit dynamic model. Solar Energy, 75(2):143-152, 2003.

Christian Cristofari, Gilles Notton, Philippe Poggi, and Alain Louche. Modelling and performance of a copolymer solar water heating collector. Solar Energy, 72(2):99-112, 2002.

Swapnil Dubey and GN Tiwari. Thermal modeling of a combined system of photovoltaic thermal (pv/t) solar water heater. Solar energy, 82(7): 602-612, 2008.

John A Duffie and William A Beckman. Solar engineering of thermal processes, fourth editio, 2013.

LW Florschuetz. Extension of the hottel-whillier model to the analysis of combined photovoltaic/thermal flat plate collectors. Solar energy, 22(4): 361-366, 1979.

HP Garg and RS Adhikari. Transient simulation of conventional hybrid photovoltaic/thermal (pv/t) air heating collectors. International journal of energy research, 22(6):547-562, 1998.

Wei He, Tin-Tai Chow, Jie Ji, Jianping Lu, Gang Pei, and Lok-shun Chan. Hybrid photovoltaic and thermal solar-collector designed for natural circulation of water. Applied energy, 83(3):199-210, 2006.

Adel A Hegazy. Comparative study of the performances of four photovoltaic/thermal solar air collectors. Energy Conversion and management, 41 (8):861-881, 2000.

BJ Huang, TH Lin, WC Hung, and FS Sun. Performance evaluation of solar photovoltaic/thermal systems. Solar energy, 70(5):443-448, 2001.

Jie Ji, Tin-Tai Chow, and Wei He. Dynamic performance of hybrid photovoltaic/thermal collector wall in hong kong. Building and Environment, 38(11):1327-1334, 2003.

CS Malvi, DW Dixon-Hardy, and R Crook. Energy balance model of combined photovoltaic solar-thermal system incorporating phase change material. Solar Energy, 85(7):1440-1446, 2011.

Nacer K M'Sirdi, Mohamed BenAbdellatif, Giuseppe Marco Tina, and Aziz Naamane. Dynamic coupled electrical and thermal model for pv-t solar energy collectors. In 2018 5th International Symposium on Environment-Friendly Energies and Applications (EFEA), pages 1-8. IEEE, 2018.

Mohamed El Amine Slimani, Madjid Amirat, Ildikó Kurucz, Sofiane Bahria, Abderrahmane Hamidat, and Wafa Braham Chaouch. A detailed thermal-electrical model of three photovoltaic/thermal (pv/t) hybrid air collectors and photovoltaic (pv) module: Comparative study under algiers climatic conditions. Energy conversion and management, 133:458-476, 2017.

Arvind Tiwari and MS Sodha. Performance evaluation of solar pv/t system: an experimental validation. Solar energy, 80(7):751-759, 2006.

Zain Ul Abdin and Ahmed Rachid. Modeling, identification and control of photovoltaic/thermal solar panel. In 2020 IEEE Conference on Control Technology and Applications (CCTA), pages 1-6. IEEE, 2020.

Zain Ul Abdin and Ahmed Rachid. A survey on applications of hybrid pv/t panels. Energies, 14(4), 2021.

Herman A Zondag, DW de de Vries, WGJ Van Helden, RJ Ch van Zolingen, and AA Van Steenhoven. The thermal and electrical yield of a pv-thermal collector. Solar energy, 72(2):113-128, 2002. 